\title{
Latihan power otot lengan untuk kecepatan push dalam olahraga hockey
}

\section{Arm muscle power training for push speed in hockey}

\author{
Ali Budiman', Gani Dwi Prabowo \\ 1,2 Program studi PJKR, STKIP Pasundan, Cimahi, Jawa Barat, 40512, Indonesia
}

\begin{abstract}
Abstrak
Tujuan penelitian ini untuk mengetahui pengaruh latihan power otot lengan terhadap kecepatan push olahraga hockey. Metode penelitian yang digunakan adalah metode eksperimen dengan desain one group pretest-posttest design. Populasi dalam penelitian ini adalah atlet Jalak Harupat Hockey Academy yang terdiri atas 46 orang. Teknik purposive sampling digunakan dalam pemilihan sampel penelitian, sehingga diperoleh 20 orang atlet yang memenuhi kriteria penelitian.Instrumen yang digunakan untuk mengetahui kecepatan push menggunakan alat sklz sport radar. Pengolahan data dilakukan dengan menggunakan metode paired sample T-test dalam aplikasi SPSS versi 23. Hasil penelitian memperlihatkan nilai sig. $0,0000>0,5$ yang berarti bahwa latihan power otot lengan memiliki pengaruh yang signifikan terhadap peningkatan kecepatan push dalam olahraga hockey. Berdasarkan hasil penelitian ini dapat ditarik kesimpulan bahwa aspek power pada lengan atlet hockey sangatlah berpengaruh terhadap kecepatan push yang mereka miliki. Karena selain akurat, kecepatan push juga perlu dimiliki oleh seorang atlet hockey guna menunjang permainan mereka.
\end{abstract}

Kata kunci: power otot lengan, kecepatan push

\begin{abstract}
The purpose of this study was to determine the effect of arm muscle power training on the speed of push hockey. The research method used was an experimental method with one group pretest-posttest design. The population in this study was the Jalak Harupat Hockey Academy athlete consisting of 46 people. Purposive sampling technique is used in the selection of research samples, so that 20 athletes are obtained who meet the research criteria. The instrument used to determine the speed of push uses the SKLZ sport radar tool. Data processing was performed using the paired sample T-test method in SPSS version 23. The results of the study showed the sig value. 0.0000>0.5 which means that arm muscle power training has a significant effect on increasing the speed of push in hockey. Based on the results of this study it can be concluded that the aspect of power in the arms of hockey athletes is very influential on the speed of push they have. Because besides being accurate, push speed also needs to be owned by a hockey athlete to support their game.
\end{abstract}

Keywords: Arm muscle power,push speed.

\section{PENDAHULUAN}

Olahraga hockey merupakan salah satu jenis olahraga permainan bola kecil. Olahraga ini sudah banyak dikenal di masyarakat dunia, dan sering dipertandingkan pada event-event internasional. Di Indonesia pun, olahraga hockey sudah cukup dikenal, terutama pada kalangan perguruan tinggi karena banyak event-event kejuaraan antar 
perguruan tinggi yang dilaksanakan di Indonesia ini. Memasuki kehidupan modern, akhirakhir ini olahraga hockey mulai popular dan banyak diminati oleh anak-anak sekolah baik tingkat menengah pertama hingga menengah atas, bahkan ada juga siswa sekolah dasar yang menggemarinya (Muhammad, 2018).

Dalam pelaksanaannya, olahraga hockey merupakan jenis olahraga yang memang memerlukan teknik dan berbagai komponen kondisi fisik yang baik (Timmerman et al., 2019). Para atlet dituntut untuk bergerak kesana kemari selama permainan, dengan mengandalkan berbagai teknik yang memerlukan keterampilan, strength dan power dalam pelaksanaannya. Guna menunjang itu semua, seorang atlet harus melatih berbagai komponen kondisi fisik tersebut agar dia dapat bermain hockey dengan baik.

Banyak teknik dalam olahraga hockey yang harus dikuasai seorang atlet, yang paling mendasar dan sering digunakan adalah teknik push, karena rata-rata semua pemain hockey pada saat bertanding kebanyakan memakai teknik push baik untuk mencetak gol maupun memberikan umpan kepada rekan satu tim. Keterampilan push yang baik dapat menunjang permainan yang baik dan efektif.

Maka dari itu, teknik push adalah keterampilan yang harus dikuasai oleh semua anggota tim. Karena push merupakan teknik untuk membangun kerjasama dalam permainan hockey. Tanpa ada push tidak akan terbentuk kerjasama tim yang baik. Push merupakan teknik mengumpan bola yang sering digunakan oleh pemain dalam sebuah pertandingan.

Dalam pelaksanaan teknik push, otot yang dominan digunakan adalah otot lengan. Sehingga selain berlatih teknik, berbagai jenis latihan untuk meningkatkan kekuatan (strength) otot lengan perlu dilakukan. Akan tetapi tidak hanya kekuatan (strength) saja yang harus dilatih, melainkan power pun harus dilatih juga.

Dengan dilatihnya power otot lengan, diharapkan juga kecepatan bola hasil dari teknik push dapat meningkat. Cepatnya bola bergulir akan berimbas terhadap efektifitas permainan hockey itu sendiri.

Kenyataan di lapangan, hasil pengamatan penulis, ketika melihat klub Jalak Harupat Hockey Academy baik saat berlatih maupun bertanding, efektifitas passing terutama saat penggunaan teknik push mereka sangatlah kurang. Terlihat dari lemahnya bola hasil push mereka yang mengakibatkan tempo permainan menjadi lambat dan mudah dipotong oleh lawan.

Berdasarkan hal tersebut, maka perlu dilakukan perlakukan atau treatment berupa latihan power otot lengan guna meningkatkan kecepatan bola hasil push pemain Jalak Hockey Academy. 


\section{METODE}

Untuk membuktikan kebenaran dari hipotesis yang penulis ajukan maka penulis melakukan penelitian dengan menggunakan metode eksperimen, yaitu penelitian yang dilaksanakan melalui eksperimentasi atau percobaan. Sementara desain yang digunakan adalah The One Group Pretest-Posttest Design (Fraenkel \& Wallen, 2008). Berikut ini adalah gambar desain peneletiannya :

\section{O1 $\quad$ X $\quad 02$}

Gambar 1. The One Group PretestPosttest Design(Fraenkel \& Wallen, 2008)

Keterangan:

$\mathrm{X}:$ Treatment/Perlakuan yang diberikan

O1: Tes awal (pretest) kelompok eksperimen

O2: Tes akhir (posttest) kelompok eksperimen

Populasi yang digunakan dalam penelitian ini adalah atlet Jalak Hockey Academy. Yang berjumlah 47 orang, terdiri dari berbagai kalangan usia mulai dari siswa SD, SMP, maupun SMA.

Teknik sampling yang digunakan adalah Teknik Purposive Sampling yaitu dilakukan dengan cara mengambil subjek bukan didasarkan atas strata, random atau daerah tetapi didasakan atas adanya tujuan tertentu.Sehingga diperoleh 20 orang sebagai sampel dengan kriteria :

a) Atlet yang bersedia menjadi responden

b) Atlet yang rentang usia 16-19 tahun

c) Hadir saat pengukuran power otot lengan dan bersedia diukur.

Instrumen yang digunakan dalam penelitian untuk menghitung hasil tes kecepatan bola menggunakan suatu alat yang disebut SKLZ sport radar dalam satuan $\mathrm{km} / \mathrm{jam}$. Beriku ini gambar dari instrument yang digunakan:

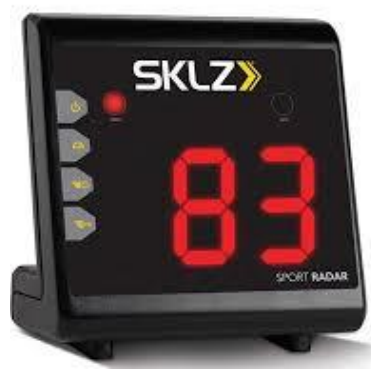

Gambar 2. SKLZ Sport Radar 
Selanjutnya Penulis menggunakan aplikasi SPSS versi 23 dengan melakukan uji Paired Sample T-test untuk mengolah data yang telah dikumpulkan.

\section{HASIL DAN PEMBAHASAN}

\section{Hasil}

Setelah dilakukan pengambilan data pada sampel yang digunakan, diperoleh hasil pretest kecepatan bola teknik push sebagai berikut :

Tabel 1. Hasil Pretest Kecepatan Bola Push

\begin{tabular}{|c|c|c|c|c|c|}
\hline No & Nama & Skor & No & Nama & Skor \\
\hline 1 & Rifa & 55 & 11 & Ilham & 83 \\
\hline 2 & Bunga & 55 & 12 & Bena & 61 \\
\hline 3 & Asri & 55 & 13 & Arib & 75 \\
\hline 4 & Tata & 50 & 14 & Angga & 58 \\
\hline 5 & Salma & 48 & 15 & Nurul & 70 \\
\hline 6 & Nisa & 60 & 16 & Akmal & 55 \\
\hline 7 & Repa & 40 & 17 & Dewa & 75 \\
\hline 8 & Adna & 52 & 18 & Ali & 64 \\
\hline 9 & Fitri & 48 & 19 & Salman & 53 \\
\hline 10 & Jojo & 55 & 20 & Irsyad & 57 \\
\hline \multicolumn{5}{|c|}{ Skor Rata-rata } & 58.45 \\
\hline
\end{tabular}

Berdasarkan tabel 1 di atas, dapat terlihat bagaimana skor paling terendah yang diperoleh adalah 40, dan paling tinggi adalah 83, dengan skor rata-rata sebesar 58,45.

Sementara itu untuk hasil pretest kecepatan bola teknik push dapat dilihat pada tabel 2 berikut ini:

Tabel 2. Hasil Posttest Kecepatan Bola Push

\begin{tabular}{llllll}
\hline No & Nama & Skor & No & Nama & Skor \\
\hline $\mathbf{1}$ & Rifa & 62 & $\mathbf{1 1}$ & Ilham & 86 \\
$\mathbf{2}$ & Bunga & 58 & $\mathbf{1 2}$ & Bena & 70 \\
$\mathbf{3}$ & Asri & 60 & $\mathbf{1 3}$ & Arib & 82 \\
$\mathbf{4}$ & Tata & 58 & $\mathbf{1 4}$ & Angga & 65 \\
$\mathbf{5}$ & Salma & 60 & $\mathbf{1 5}$ & Nurul & 85 \\
$\mathbf{6}$ & Nisa & 65 & $\mathbf{1 6}$ & Akmal & 50 \\
$\mathbf{7}$ & Repa & 48 & $\mathbf{1 7}$ & Dewa & 80 \\
$\mathbf{8}$ & Adna & 55 & $\mathbf{1 8}$ & Ali & 67 \\
$\mathbf{9}$ & Fitri & 60 & $\mathbf{1 9}$ & Salman & 60 \\
$\mathbf{1 0}$ & Jojo & 64 & $\mathbf{2 0}$ & Irsyad & 67 \\
\hline \multirow{2}{*}{ Skor Rata-rata } & & & & 6 \\
\end{tabular}

Berdasarkan tabel 2 di atas, dapat terlihat bagaimana skor paling terendah yang diperoleh adalah 48, dan paling tinggi adalah 86, dengan skor rata-rata sebesar 65,10.

Selanjutnya penulis melakukan uji normalitas data. Hasil yang diperoleh dalam uji normalitas data tersebut dapat dilihat pada table 3 berikut: 
Tabel 3. Hasil Uji Normalitas

Tests of Normality

\begin{tabular}{|c|c|c|c|c|c|c|c|}
\hline & \multicolumn{3}{|c|}{$\begin{array}{l}\text { Kolmogorov- } \\
\text { Smirnov }{ }^{\mathrm{a}}\end{array}$} & \multicolumn{4}{|c|}{ Shapiro-Wilk } \\
\hline & $\begin{array}{l}\text { Statis } \\
\text { tic }\end{array}$ & Df & Sig. & $\begin{array}{l}\text { Stati } \\
\text { stic }\end{array}$ & $\mathrm{df}$ & & Sig. \\
\hline $\begin{array}{l}\text { pre } \\
\text { test }\end{array}$ & .179 & 20 & .093 & .928 & & 0 & .142 \\
\hline $\begin{array}{l}\text { post } \\
\text { test }\end{array}$ & .180 & 20 & .088 & .916 & & 0 & .084 \\
\hline
\end{tabular}

a. Lilliefors Significance Correction

Berdasarkan data tersebut didapat signifikansi untuk pretest-postest dengan tes kolmogorov smirnov berturut turut sebesar 0,093 dan 0,088. Dari data tersebut dapat diketahui bahwa data yang diperoleh $>0,05$ maka data tesebut dapat dinyatakan berdistribusi normal.

Setelah mengetahui tingkat kenormalan data, maka selanjutnya dilakukan uji homogenitas. Uji homogenitas digunakan untuk mengetahui apakah suatu varian (keberagaman) data dari dua atau lebih kelompok bersifat homogen (sama) atau heterogen (tidak sama).Data hasil uji homogenitas pada penelitian ini dapat di lihat pada tabel 4 di bawah ini:

Tabel 4. Hasil Uji Homogenitas

\begin{tabular}{|c|c|c|c|c|c|}
\hline & & $\begin{array}{l}\text { Levene } \\
\text { Statistic }\end{array}$ & df1 & $\mathrm{df2}$ & Sig. \\
\hline & $\begin{array}{l}\text { Based on } \\
\text { Mean }\end{array}$ & .013 & 1 & 38 & .909 \\
\hline & $\begin{array}{l}\text { Based on } \\
\text { Median } \\
\text { Based on }\end{array}$ & .071 & 1 & 38 & .791 \\
\hline$\underset{\Phi}{\Phi}$ & $\begin{array}{l}\text { Median and } \\
\text { with adjusted } \\
\text { df }\end{array}$ & .071 & 1 & 37.62 & .791 \\
\hline $\begin{array}{l}\overline{\bar{g}} \\
\stackrel{\widetilde{c}}{c}\end{array}$ & $\begin{array}{l}\text { Based on } \\
\text { trimmed mean }\end{array}$ & .020 & 1 & 38 & .888 \\
\hline
\end{tabular}

Berdasarkan dari data tersebut diperoleh hasil homogenitas sebesar 0,909 > 0,05, sehingga dapat disimpulkan bahwa varian data postest hasil kecepatan push bersifat homogen.

Setelah melakukan uji prasarat analisis di atas, selanjutnya adalah melakukan pengujian hipotesis penelitian.

Data hasil uji hipotesis penelitian, dapat dilihat pada table 5 berikut ini : 


\section{Tabel 5. Hasil Uji Paired Sample T-test}

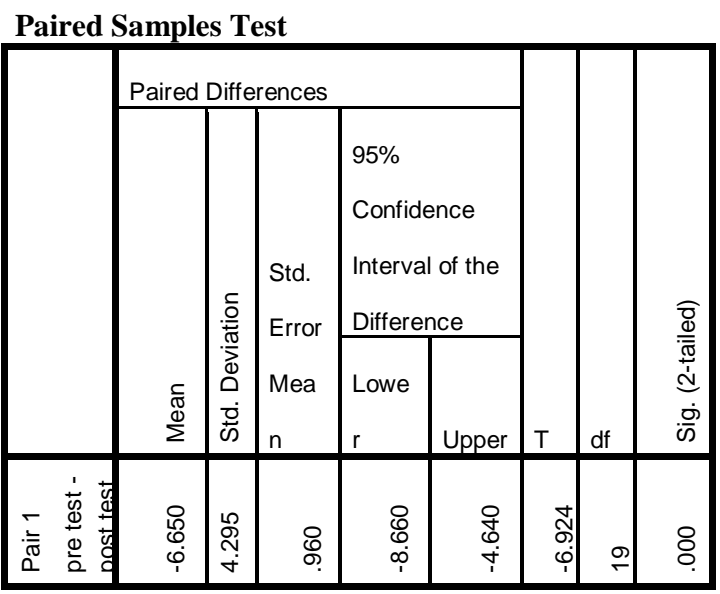

Berdasarkan data di atas dapat diketahui bahwa nilai sig 2-tailed sebesar 0,0000 < 0,05, maka dapat disimpulkan ada perbedaan atau peningkatan rata-rata yang signifikan dari pretest dengan perlakuan latihan power otot lengan terhadap posttest hasil kecepatan push. Sehingga dapat disimpulkan bahwa latihan power otot lengan berpengaruh dan mampu meningkatkan kecepatan hasil teknik push olahraga hockey.

\section{Pembahasan}

Data hasil penelitian yang telah di deskripsikan di atas, menunjukkan bahwa adanya peningkatan pada kecepatan push pada atlet Jalak harupat Hockey Academy. Hal tersebut menunjukkan adanya pengaruh dari latihan power otot lengan yang diberikan.

Olahraga Hockey sendiri tidak dapat lepas dari kemampuan kondisi fisik atletnya. Karena berdasarkan hasil studi performa di lapangan, rata-rata pemain wanita selama pertandingan bergerak dan berlari berkisar antara 5,5-6,6 km, dengan rata-rata denyut jantung (HR) kira-kira 170 detak/menit. Sementara untuk pemain pria, ditemukan bahwa selama pertandingan jarak total yang dicakup per posisi bermain berkisar dari $5,82 \mathrm{~km}$ hingga $10 \mathrm{~km}$ (Lidor \& Ziv, 2015). Selain itu olahraga ini juga menuntut para pemain untuk berlari dengan intesnsitas yang tinggi (Vescovi, 2016). Ini berarti olahraga hockey merupakan olahraga yang memerlukan kemampuan aerobik yang baik. Tapi, tidak hanya kemampuan aerobik saja yang dibutuhkan, namun aspek lain seperti kekuatan dan power juga perlu dimiliki.

Aspek kekuatan dan power tersebut sangat menunjang terhadap kemampuan teknik yang dimilik atlet (Abade et al., 2019; Thiele et al., 2020). Dalam olahraga hockey berbagai macam teknik yang harus dimiliki diantara lain adalah teknik push, tapping, hit, stop, scoop, flick, maupun dribbling(Barth \& Nordmann, 2007).Agar semua teknik ini dapat dilakukan dengan baik oleh atlet, maka selain latihan drill yang berfokuskan pada 
penguasaan teknik tersebut, latihan-latihan beban untuk meningkatkan kemampuan otot yang menunjangnya pun perlu dilakukan.

Pada penelitian ini lebih difokuskan terhadap teknik push dalam olahraga hockey. Teknik pushini bertujuan untuk mendorong bola dengan kuat kedepan dan menyusur tanah. Tidak ada ayunan dalam melakukan teknik push. Gerakan lebih banyak dilakukan oleh pergelangan tangan yang kuat dan memindahkan berat badan dari kaki kanan ke kaki kiri bersama dengan itu bola didorong dengan kuat kedepan.(Budiarto, 2014).

Agar bola yang didorong melalui teknik push ini menjadi lebih cepat, maka diberikan perlakuan berupa latihan power, karena teknik push ini sangat sering digunakan dalam melakukan passing, dan passing yang cepat dan akurat berpengaruh terhadap efektifitas permainan (Vinson \& Peters, 2016). Latihan power diberikan agar mampu meningkatkan power atlet yang dulunya lemah menjadi lebih kuat pada otot yang dominan, dalam hal ini adalah power otot lengan selama 16 pertemuan. Latihan power otot lengan diberikan karena dalam olahraga hockey ini pemain memainkan bola dengan menggunakan stik yang digenggam kuat oleh tangan mereka. Maka dari itu olahraga yang dominan menggunakan tangan maupun menggunakan alat yang digenggam oleh tangan, bagian otot lenganlah yang dominan dan perlu dilatih (Prayadi \& Rachman, 2013; Vigouroux et al., 2019).

Latihan power otot lengan yang diberikan berupa latihan stall bars hoopsdengan repetisi dan set yang telah ditentukan melalui program latihan yang penulis buat.

Latihan power otot lengan jenis ini dipilih karena berdasarkan penelitian, latihan stall bars hoops lebih baik daripada latihan decline push up (Purba, 2014).

Adapun jenis latihan lain yang dapat meningkatkan power lengan dalam olahraga hockey seperti Medicine Ball Side Throw dengan Kettlebell Side Swing (Ramdhan \& Sunaryadi, 2019), tidak penulis gunakan dikarenakan latihan tersebut lebih dominan dan menyerupai gerakan teknik hit.

Sehingga setelah diberikan latihan power otot lengan berupa stall bars hoops ini terjadi peningkatan pada posttest kecepatan bola hasil push atlet. Untuk pengambilan data kecepatan bola, penulis menggunakan alat yang dinamakan SKLZ sport radar. Alat ini merupakan suatu produk yang dapat mendeteksi kecepatan suatu benda dalam satuan $\mathrm{km} / \mathrm{jam}$.

Diketahui bahwa hasil analisis data nilai sig 2-tailed sebesar $0,0000<0,05$, yang berarti latihan power lengan ini memiliki pengaruh yang signifikan terhadap kecepatan push atlet. Poin peningkatan yang terjadi dari rata-rata nilai pretest hingga posttest adalah sebanyak 6,650 . 
Hasil penelitian ini sekaligus membuktikan hasil penelitian lain yang menyebutkan bahwa adanya kontribusi dari otot lengan terhadap keterampilan teknik olahraga hockey, seperti dalam pelaksanaan teknik penalty stroke di mana power otot lengan memberikan sumbangan $13,01 \%$, kekuatan genggaman memberikan sumbangan $21,00 \%$, fleksibilitas pergelangan tangan memberikan sumbangan 12,63\%, kekuatan tungkai memberikan sumbangan 38,54\%, sedangkan power otot lengan, kekuatan genggaman, fleksibilitas pergelangan tangan, dan kekuatan tungkai secara bersama-sama memberikan sumbangan terhadap kemampuan tembakan penalti hockey yaitu $85,18 \%$ dan sisanya yaitu $14.82 \%$ dipengaruhi oleh variabel lain yang tidak masuk dalam penelitian (Nurhidayah et al., 2014). Dalam penelitian tersebut power otot lengan berperan terhadap kecepatan bola yang dilepaskan ketika melakukan penalti.

\section{KESIMPULAN}

Berdasarkan hasil penelitian ini dapat ditarik kesimpulan bahwa aspek power pada lengan atlet hockey sangatlah berpengaruh terhadap kecepatan push yang mereka miliki. Karena selain akurat, kecepatan push juga perlu dimiliki oleh seorang atlet hockey guna menunjang permainan mereka.

Maka dari itu aspek ini jangan diabaikan oleh pelatih, karena sejatinya keterampilan teknik harus didampingi juga oleh kondisi fisik yang mumpuni.

\section{DAFTAR PUSTAKA}

Abade, E., Sampaio, J., Santos, L., Gonçalves, B., Sá, P., Carvalho, A., Gouveia, P., \& Viana, J. (2019). Effects of using compound or complex strength-power training during in-season in team sports. Research in Sports Medicine, 00(00), 1-12. https://doi.org/10.1080/15438627.2019.1697927

Barth, K., \& Nordmann, L. (2007). Learning Field Hockey. Meyer \& Meyer Sport.

Budiarto, F. T. (2014). Perbandingan Kecepatan Laju Bola pada Jenis Pukulan Push, Hit, dan Flick pada Permainan Hockey. Jurnal Kesehatan Olahraga, 2(2), 120-128.

Fraenkel, J. R., \& Wallen, N. E. (2008). How to Design and Evaluate Research in Education (7th ed.). McGraw-Hill Higher Education.

Lidor, R., \& Ziv, G. (2015). On-field performances of female and male field hockey players - A review. International Journal of Performance Analysis in Sport, 15(1), 20-38. https://doi.org/10.1080/24748668.2015.11868774

Muhammad, H. N. (2018). Evaluasi Konteks Program Pembinaan Prestasi Cabang Olahraga Hockey Di Jawa Timur. JOSSAE: Journal of Sport Science and Education, 3(1), 7. https://doi.org/10.26740/jossae.v3n1.p7-11

Nurhidayah, E., Rahayu, S., \& Waluyo, M. (2014). Sumbangan Power Otot Lengan, 
Kekuatan Genggaman, Fleksibilitas Pergelangan Tangan dan Kekuatan Tungkai Terhadap Kemampuan Tembakan Penalti pada Hockey. Journal of Sport Sciences and Fitness, 3(1), 31-36.

Prayadi, H. Y., \& Rachman, H. A. (2013). Pengaruh Metode Latihan dan Power Lengan terhadap Kemampuan Smash Bulutangkis. Jurnal Keolahragaan, 1(3), 63-71. https://doi.org/https://doi.org/10.21831/jk.v1i1.2346

Purba, P. H. (2014). Perbedaan Pengaruh Latihan Decline Push-Up Dengan Latihan Stall Bars Hops Terhadap Power Otot Lengan Dan Kecepatan Pukulan Gyaku Tsuki Chudan Pada Atlet Putra Karateka Wadokai Dojo Unimed Tahun 2013. Jurnal Ilmu Keolahragaan, 13(1), 23-33. http://digilib.unimed.ac.id/id/eprint/1375

Ramdhan, M. R., \& Sunaryadi, Y. (2019). Perbandingan Latihan Medicine Ball Side Throw dengan Kettlebell Side Swing terhadap Peningkatan Kecepatan Hit Cabang Olahraga Hockey. Jurnal Kepelatihan Olahraga, 11(2), 83-87. https://ejournal.upi.edu/index.php/JKO/article/view/20313/10237

Thiele, D., Prieske, O., Chaabene, H., \& Granacher, U. (2020). Effects of strength training on physical fitness and sport-specific performance in recreational, sub-elite, and elite rowers: A systematic review with meta-analysis. Journal of Sports Sciences, OO(00), 1-10. https://doi.org/10.1080/02640414.2020.1745502

Timmerman, E. A., Savelsbergh, G. J. P., \& Farrow, D. (2019). Creating Appropriate Training Environments to Improve Technical, Decision-Making, and Physical Skills in Field Hockey. Research Quarterly for Exercise and Sport, 90(2), 180-189. https://doi.org/10.1080/02701367.2019.1571678

Vescovi, J. D. (2016). Locomotor, Heart-Rate, and Metabolic Power Characteristics of Youth Women's Field Hockey: Female Athletes in Motion (FAiM) Study. Research Quarterly for Exercise and Sport, 87(1), 68-77. https://doi.org/10.1080/02701367.2015.1124972

Vigouroux, L., Devise, M., Cartier, T., Aubert, C., \& Berton, E. (2019). Performing pullups with small climbing holds influences grip and biomechanical arm action. Journal of Sports Sciences, 37(8), 886-894. https://doi.org/10.1080/02640414.2018.1532546

Vinson, D., \& Peters, D. M. (2016). Position-specific performance indicators that discriminate between successful and unsuccessful teams in elite women's indoor field hockey: implications for coaching. Journal of Sports Sciences, 34(4), 311-320. https://doi.org/10.1080/02640414.2015.1055292 